\title{
Overexpression of E74-like transformation-specific transcription factor 3 promotes cellular proliferation and predicts poor prognosis in ovarian cancer
}

\author{
YAO LIU, SHOURONG WANG, RUIQI ZHOU, WENXUE LI and GUIYU ZHANG \\ Department of Gynecology and Obstetrics, Qilu Hospital, Cheeloo College of Medicine, \\ Shandong University, Jinan, Shandong 250012, P.R. China
}

Received January 3, 2021; Accepted July 12, 2021

DOI: $10.3892 / \mathrm{ol} .2021 .12971$

\begin{abstract}
E74-like E26 transformation-specific (ETS) transcription factor 3 (ELF3), is a member of the ETS transcription factor family, and has been characterized as an epithelial cell-specific transcription factor. The role of ELF3 in tumor progression remains to be elucidated. Previous studies have indicated that loss of ELF3 mRNA and protein expression was associated with poor outcomes in ovarian cancer (OC). By contrast, the present study demonstrated that ELF3 was upregulated in OC, using data from The Cancer Genome Atlas, and elevated expression levels of ELF3 were associated with a poor prognosis. ELF3 promoted OC cell proliferation in vitro and in vivo. The present study revealed that ELF3 inhibited apoptosis and reduced the cisplatin sensitivity of OC cells. Furthermore, the mTOR pathway was found to be activated by ELF3. Collectively, the results of the present study indicated the role of ELF3 in the development and pathogenesis of OC.
\end{abstract}

\section{Introduction}

Epithelial ovarian cancer (EOC) is the most fatal gynecological cancer, with a survival rate of $46 \%$ at 5 years post-diagnosis (1). The high death-to-incidence rate is attributed to the advanced stage of the disease at the time of diagnosis. Due to the asymptomatic nature of EOC, $75 \%$ of patients with ovarian cancer (OC) are diagnosed at an advanced stage (2). In the late stages of disease, there is a 5-year relative survival rate of $29 \%$, compared with $92 \%$ in the early stages of disease (3). It has also been revealed that $15 \%$ of women diagnosed with EOC have a genomic predisposition to developing the disease, including

Correspondence to: Dr Guiyu Zhang, Department of Gynecology and Obstetrics, Qilu Hospital, Cheeloo College of Medicine, Shandong University, 107 Wenhuaxi Road, Jinan, Shandong, P.R. China

E-mail: zgy5566@sdu.edu.cn

Key words: E74-like ETS transcription factor 3, ovarian cancer, proliferation, poor prognosis, cisplatin resistance, mTOR pathway the presence of mutations in causative breast cancer genes, BRCA1 and BRCA2, found in $65-75 \%$ of hereditary EOC cases (2). Therefore, the identification of further diagnostic and prognostic markers of EOC is critical.

E74-like E26 transformation-specific (ETS) transcription factor 3 (ELF3) is located on chromosome 1q32.1, and encodes a protein 371 amino acids in length. ELF3 is an epithelial cell-specific ETS transcription factor, and a member of the epithelial cell-specific sub-group of the larger ETS transcription factor family (4). The results of a previous study demonstrated that inactivating and splice-site mutations in ELF3 occur in $\sim 6 \%$ of mucinous OCs (5). Yeung et al (6) suggested that ELF3 played a role in tumor suppression, as loss of ELF3 mRNA and protein expression was associated with a poor outcome in OC. On the other hand, ELF3 was also found to promote the progression of colorectal cancer and hepatocellular carcinoma $(7,8)$.

In order to investigate its biological role in $\mathrm{OC}$, the aim of the present study was to analyze the expression of ELF3 in $\mathrm{OC}$, and to determine the effects of ELF3 on OC cell proliferation and cisplatin sensitivity. The mechanism by which ELF3 promotes OC progression was also investigated.

\section{Materials and methods}

Bioinformatics analysis. The top 20 upregulated genes in $\mathrm{OC}$, found using TCGA and the Genotype-Tissue Expression Portal (GTEx), were analyzed for their chromosomal distribution using the Gene Expression Profiling Interactive Analysis (GEPIA) website (http://gepia.cancer-pku.cn/) (9), with a threshold of $\log 2$ FoldChange $>3 ; \mathrm{q}<0.01$. The genetic alteration of ELF3, and the association between ELF3 mRNA expression and genetic copy number alteration in OC, was analyzed using cBioPortal (www.cbioportal.org) (10). GEPIA was also used to analyze the expression of ELF3 in OC and non-cancerous control tissues, based on TCGA and GTEx data. The protein expression of ELF3 in OC and non-cancerous ovarian tissues was determined using The Human Protein Atlas (https://www. proteinatlas.org/). The expression of ELF3 in OC, based on individual cancer stages and patient age, was analyzed in UALCAN (http://ualcan.path.uab.edu/index.html) (11). Kaplan-Meier-plotter (http://kmplot.com/analysis/) (12) was 
used to analyze the overall and progression-free survival rates of OC and ELF3 mRNA expression based on the Kaplan-Meier-plotter cohort, and GEPIA was used to perform survival analysis on TCGA cohort.

Cell lines and culture. A2780 and SKOV3 cell lines were purchased from the American Type Culture Collection. A2780 cells were cultured in DMEM and SKOV3 cells were cultured in McCoy's 5A medium, both supplemented with 10\% FBS (all Gibco; Thermo Fisher Scientific, Inc.). A2780/DDP and SKOV3/DDP cell lines were established by long-term exposure to cisplatin. Firstly, cells were treated with $5 \mu \mathrm{g} / \mathrm{ml}$ cisplatin for $1 \mathrm{~h}$, and then cultured in medium without cisplatin. After 3-5 days (at 70-80\% confluency), the cells were treated with $5 \mu \mathrm{g} / \mathrm{ml}$ cisplatin once more. When the cells were resistant to the current cisplatin concentration, the concentration was incrementally increased until reaching $200 \mu \mathrm{g} / \mathrm{ml}(5,10$, $20,50,100$ and $200 \mu \mathrm{g} / \mathrm{ml})$. The cells were than cultured in medium with $200 \mu \mathrm{g} / \mathrm{ml}$ cisplatin to retain resistance. All cells were maintained at $37^{\circ} \mathrm{C}\left(5 \% \mathrm{CO}_{2}\right)$ in a humified incubator.

Plasmid construction and transfection. To construct the overexpression vector, the open reading frame sequence of ELF3 was amplified and cloned into the pLenti-C-Myc-DDK-IRES-Puro (pCMV) vector (OriGene Technologies, Inc.). 293T cells (ATCC) were transfected with the pCMV-ELF3 vector $(8 \mu \mathrm{g})$, along with pMD2.G $(4 \mu \mathrm{g})$ and psPAX2 $(8 \mu \mathrm{g})$ plasmids for lentivirus production. Culture medium was collected 48 and $72 \mathrm{~h}$ after transfection, and cell debris was removed by centrifugation with $4,000 \times \mathrm{g}$ for $10 \mathrm{~min}$ at $4^{\circ} \mathrm{C}$. The supernatants were clarified with a $0.45-\mu \mathrm{m}$ filter and stored at $-80^{\circ} \mathrm{C}$. A2780 cells were infected with lentivirus for $48 \mathrm{~h}$ (multiplicity of infection, 10 for A2780 infection and 30 for SKOV3 infection) and subsequently cultured for 2 weeks in DMEM medium (Gibco; Thermo Fisher Scientific.) containing $2 \mu \mathrm{g} / \mathrm{ml}$ puromycin (Merck KGaA) to generate stable expression cell lines. Stable cell line maintenance was performed using $0.5 \mu \mathrm{g} / \mathrm{ml}$ puromycin. The negative control for lentiviral transfection was the backbone vector without the ELF3 CDS. ELF3 small interfering (si)RNA was purchased from Shanghai GenePharma Co., Ltd., with which SKOV3 cells were transfected using Lipofectamine ${ }^{\circledR} 2000$ (Invitrogen, Thermo Fisher Scientific, Inc.) according to the manufacturer's protocol. The ELF3 siRNA sequence was 5'-GCCAUGAGGUACUACUAC A-3', and the si-NC sequence was 5'-TTCTCCGAACGTGTC ACGT-3'. For knockdown experiments, cells were transfected with $50 \mathrm{nM}$ siRNA at $37^{\circ} \mathrm{C}$ for $24 \mathrm{~h}$. The time interval between transfection and subsequent experimentation was $48 \mathrm{~h}$.

Clonogenic assay. Cell suspensions were seeded into 6-well plates at a density of 400 cells/well, and cultured at $37^{\circ} \mathrm{C}$ for 2 weeks. The cell colonies were fixed with $100 \%$ methanol for $15 \mathrm{~min}$, and stained with $0.1 \%$ crystal violet for $30 \mathrm{~min}$ at room temperature. Colonies of $>50$ cells were counted under a light microscope. The results presented are the mean \pm standard error and represent three independent experiments.

Cellular proliferation assay. Cells were seeded into 96-well plates at a density of $10^{3}$ cells/well, and cultured at $37^{\circ} \mathrm{C}$ for 5-6 days. Next, $10 \mu 1$ Cell Counting Kit-8 (CCK-8) reagent was added to each well at the same time every day, followed by incubation for $4 \mathrm{~h}$ at $37^{\circ} \mathrm{C}$; the absorbance of each well was measured at $490 \mathrm{~nm}$ using a microplate reader. The relative proliferation rate is presented as the comparison of absorbance measured each day to the absorbance measured on the first day of the experiment. All experiments were repeated at least three times.

Xenograft experiments. The animal experiments were performed with the approval of Shandong University Animal Care and Use committee (approval no. KYLL-202011-130). A total of 10 female BALB/c-nude mice (Charles River Laboratories, Inc.) were maintained in specific pathogen-conditions (5 mice per cage) at $22^{\circ} \mathrm{C}$ (humidity, $60 \%$; ventilation rate, 15 times per hour) under a $12 \mathrm{~h} / 12 \mathrm{~h}$ light/dark cycle, with free access to food and water. Animal health was monitored every 2 days. A2780 OC cells overexpressing ELF3 (and controls cells overexpressing backbone vector) were subcutaneously injected into the mice (age, 5 weeks; weight, $18-20 \mathrm{~g} ; 5$ mice per group) at a density of $2 \times 10^{6}$ cells/mouse. The experiment lasted for 24 days, and the mice were sacrificed by cervical dislocation. The maximum tumor volume was $354.8 \mathrm{~mm}^{3}$, and was calculated according to the following formula: Volume $=1 / 2\left(\mathrm{a} \mathrm{x} \mathrm{b}^{2}\right)$ (were $\mathrm{a}$ is the long axis of the tumor, and $b$ is the short axis of the tumor).

Western blotting. Cultured cells were harvested and lysed on ice for 30 min using RIPA buffer (Beyotime Institute of Biotechnology) containing $1 \%$ PMSF and $1 \%$ sodium fluoride, with vortexing every $10 \mathrm{~min}$. The protein concentration was determined using a BCA Assay kit (Beyotime Institute of Biotechnology). A total of $30 \mu \mathrm{g}$ protein/lane was separated by SDS-PAGE (12\%) and subsequently transferred to a PVDF membrane. The membrane was blocked in 5\% skimmed milk solution at room temperature for $2 \mathrm{~h}$, and then incubated with primary antibodies at $4^{\circ} \mathrm{C}$ overnight. Following washing with TBS-Tween-20 $(0.1 \%)$, the membrane was incubated with HRP-labeled secondary antibodies $(1: 10,000$; cat. no. ab205718 and ab6789; both Abcam), and the protein bands were visualized using an ECL system (Cytiva). $\beta$-tubulin was used as the endogenous control. ImageJ software (v6; National Institutes of Health) was used for densitometric detection. The primary antibodies were as follows: ELF3 (cat. no. A6371; ABclonal Biotech Co., Ltd.; 1:1,000), Bax (cat. no. AF0120; Affinity Biosciences, Ltd.; 1:1,000), Bcl2 (cat. no. 12789-1-AP; ProteinTech Group, Inc; 1:1,000), phosphorylated (p-)mTOR (cat. no. 5536; CST Biological Reagents Co., Ltd.; 1:1,000), p-p70S6K (cat. no. 9234; CST Biological Reagents Co., Ltd.; 1:1,000), p-4EBP1 (cat. no. 9459; CST Biological Reagents Co., Ltd.; 1:1,000), mTOR (cat. no. 2983; CST Biological Reagents Co., Ltd.; 1:1,000), p70S6K (cat. no. 2708; CST Biological Reagents Co., Ltd.; 1:1,000), 4EBP1 (cat. no. 19644; CST Biological Reagents Co., Ltd.; 1:1,000) and $\beta$-tubulin (cat. no. ab6046; Abcam; 1:5,000)

$R N A$ extraction and reverse transcription-quantitative ( $R T-q)$ $P C R$. Total RNA was extracted from cultured cells using TRIzol $^{\circledast}$ reagent (Invitrogen; Thermo Fisher Scientific, Inc.) per the manufacturer's protocol. Total RNA was reverse transcribed into cDNA using the PrimeScript RT reagent kit (Takara Bio, Inc.), and qPCR was subsequently performed 
Table I. Top 20 Upregulated genes in OC based on TCGA cohort.

\begin{tabular}{|c|c|c|c|c|c|}
\hline Gene & Gene ID & $\begin{array}{l}\text { Median expression } \\
\text { (tumor) }\end{array}$ & $\begin{array}{l}\text { Median expression } \\
\text { (normal) }\end{array}$ & $\begin{array}{c}\log 2 \\
\text { (fold change) }\end{array}$ & Adjusted P-value \\
\hline CLDN3 & ENSG00000165215.6 & 532.873 & 0.100 & 8.923 & $8.49 \mathrm{e}-227$ \\
\hline WFDC2 & ENSG00000101443.17 & 2341.633 & 4.850 & 8.645 & $9.12 \mathrm{e}-162$ \\
\hline SLPI & ENSG00000124107.5 & 1338.266 & 2.718 & 8.493 & $1.01 \mathrm{e}-125$ \\
\hline FOLR1 & ENSG00000110195.11 & 375.273 & 0.095 & 8.425 & $6.55 e-143$ \\
\hline MSLN & ENSG00000102854.14 & 428.721 & 0.425 & 8.236 & $4.64 \mathrm{e}-138$ \\
\hline CD24 & ENSG00000272398.5 & 498.966 & 0.910 & 8.032 & $2.42 \mathrm{e}-158$ \\
\hline S100A1 & ENSG00000160678.11 & 505.318 & 1.180 & 7.860 & $4.29 \mathrm{e}-105$ \\
\hline CLDN4 & ENSG00000189143.9 & 265.56 & 0.460 & 7.512 & $6.91 \mathrm{e}-204$ \\
\hline LCN2 & ENSG00000148346.11 & 255.202 & 0.470 & 7.445 & $3.75 \mathrm{e}-96$ \\
\hline KRT7 & ENSG00000135480.14 & 364.872 & 1.130 & 7.425 & $3.60 \mathrm{e}-159$ \\
\hline SLC34A2 & ENSG00000157765.11 & 176.227 & 0.070 & 7.372 & $9.83 e-121$ \\
\hline CDKN2A & ENSG00000147889.16 & 258.057 & 0.635 & 7.038 & $1.42 \mathrm{e}-83$ \\
\hline EPCAM & ENSG00000119888.1 & 246.893 & 0.755 & 7.142 & $9.65 e-199$ \\
\hline KLK7 & ENSG00000169035.11 & 151.843 & 0.100 & 7.118 & $1.02 \mathrm{e}-112$ \\
\hline SMIM22 & ENSG00000267795.5 & 165.581 & 0.210 & 7.105 & $1.12 \mathrm{e}-139$ \\
\hline ELF3 & ENSG00000163435.15 & 237.617 & 0.785 & 7.063 & $3.96 \mathrm{e}-162$ \\
\hline KLK8 & ENSG00000129455.15 & 154.326 & 0.165 & 7.059 & $3.74 \mathrm{e}-152$ \\
\hline RNVU1-7 & ENSG00000206585.1 & 131.62 & 0.000 & 7.051 & $7.12 \mathrm{e}-27$ \\
\hline MAL2 & ENSG00000147676.13 & 153.974 & 0.210 & 7.001 & $3.04 \mathrm{e}-182$ \\
\hline KLK6 & ENSG00000167755.13 & 128.742 & 0.155 & 6.812 & $3.55 \mathrm{e}-94$ \\
\hline
\end{tabular}

Data were analyzed using the Gene Expression Profiling Interactive Analysis website. ELF3 is the 16th most upregulated gene in OC. Median value refers to the median expression value of the gene. OC, ovarian cancer.

using the SYBRGreen qPCR master mix (Takara Bio, Inc.), according to the manufacturers' instructions. The thermocycling conditions were as follows: Denaturation at $95^{\circ} \mathrm{C}$ for $3 \mathrm{~min}$, followed by 40 cycles at $95^{\circ} \mathrm{C}$ for $10 \mathrm{sec}, 60^{\circ} \mathrm{C}$ for $30 \mathrm{sec}$ and $72^{\circ} \mathrm{C}$ for $30 \mathrm{sec}$. The mRNA expression levels of ELF3 were quantified using the $2{ }^{-}{ }^{\Delta \mathrm{Cq}}$ method (13). GAPDH was used as the endogenous control. The primers used were as follows: ELF3 forward, 5'-AAGCGCCATTGACTTCTC AC-3' and reverse, 5'-TCCAGCAGCTCAATGATCCA-3'; and GAPDH forward, 5'-AGGTCGGAGTCAACGGATTT-3' and reverse, 5'-TGACGGTGCCATGGAATTTG-3'.

Cisplatin sensitivity assay. Cells were seeded into 96-well plates at a density of $1 \times 10^{3}$ cells/well and cultured at $37^{\circ} \mathrm{C}$ for $24 \mathrm{~h}$. Then, varying concentrations of cisplatin $(0,5,10$, 20 and $40 \mu \mathrm{g} / \mathrm{ml}$ for A2780 cells; and 0, 10,20,40 and $80 \mu \mathrm{g} / \mathrm{ml}$ for SKOV3 cells) were added to the culture medium at the same time. After a further $24 \mathrm{~h}$, cell viability was assessed using CCK-8 reagent as aforementioned.

Hematoxylin and eosin $(H \& E)$ staining. Tumor xenografts tissues were fixed with formalin (10\%, at room temperature for $48 \mathrm{~h}$ ), embedded in paraffin, and subsequently cut into $4-\mu \mathrm{m}$ sections. The tissue sections were heated at $65^{\circ} \mathrm{C}$ for $30 \mathrm{~min}$ to melt the paraffin wax and then immediately immersed in xylene. The sections were then rehydrated through decreasing concentrations of ethanol, and washed in PBS. The sections were stained with $H \& E$ (room temperature for $1 \mathrm{~min}$ ), and then dehydrated using increasing concentrations of ethanol and xylene. Finally, the sections were sealed with neutral gum. Images were captured under a light microscope (magnification, x400).

Statistical analysis. Statistical analysis was carried out using SPSS 25.0 (IBM). Unpaired Student's t-test and one-way ANOVA were used to determine significant differences. Bonferroni's post hoc test was used for pairwise comparisons following ANOVA. Survival curves were analyzed using the log-rank test. Data are presented as the mean \pm standard deviation of three independent experiments, and $\mathrm{P}<0.05$ was considered to indicate a statistically significant difference.

\section{Results}

ELF3 is commonly upregulated in OC. GEPIA was used to determine the distribution of upregulated genes in $\mathrm{OC}$, with a threshold of $\log 2$ FoldChange $<3 ; \mathrm{q}<0.01$. As demonstrated in Fig. 1A, a total of 374 genes were identified as upregulated in $\mathrm{OC}$, and were scattered on all chromosomes, excluding the $\mathrm{Y}$ chromosome. The top 20 upregulated genes in OC are listed in Table I, which includes ELF3. Further analysis of ELF3 mRNA expression using TCGA and GTEx revealed that ELF3 was significantly upregulated in OC compared with non-cancerous ovarian tissues (Fig. 1B). Genetic alterations of ELF3 were analyzed using cBioPortal. As demonstrated in Fig. 1C, $8 \%$ of OC tissues displayed genetic amplification of ELF3, though this was not associated with a significant increase in mRNA expression 
A Distribution of overexpressed genes on chromosomes

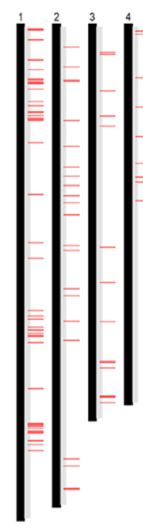

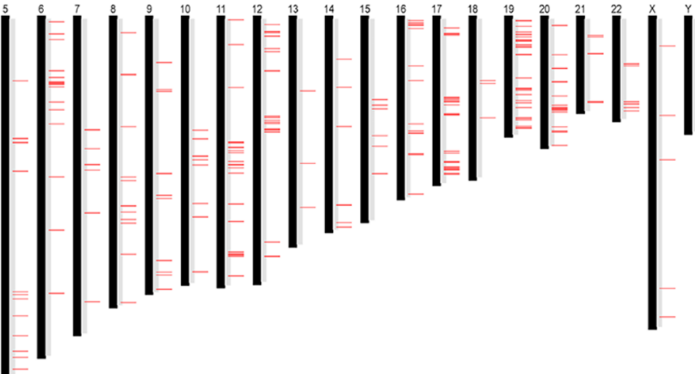

Overexpressed genes

Gene positions are based on GRCh38.p2(NCBI). 374 genes.

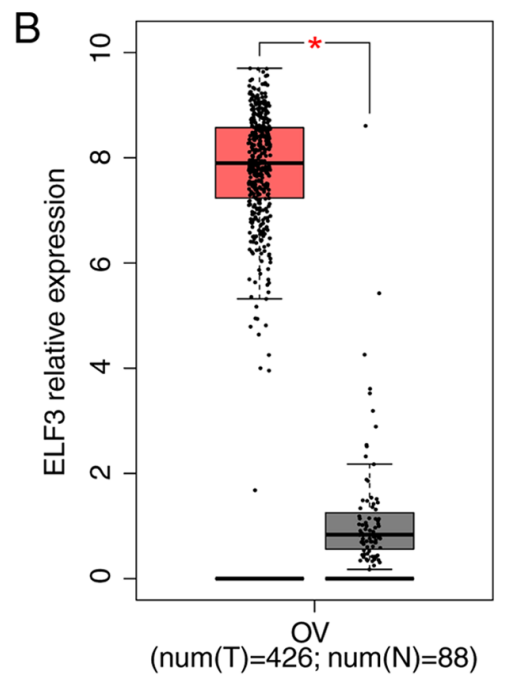

C

\section{हLF3}

Genetic alteration

Missense mutation (unknown significance)

Amplification No alterations

D

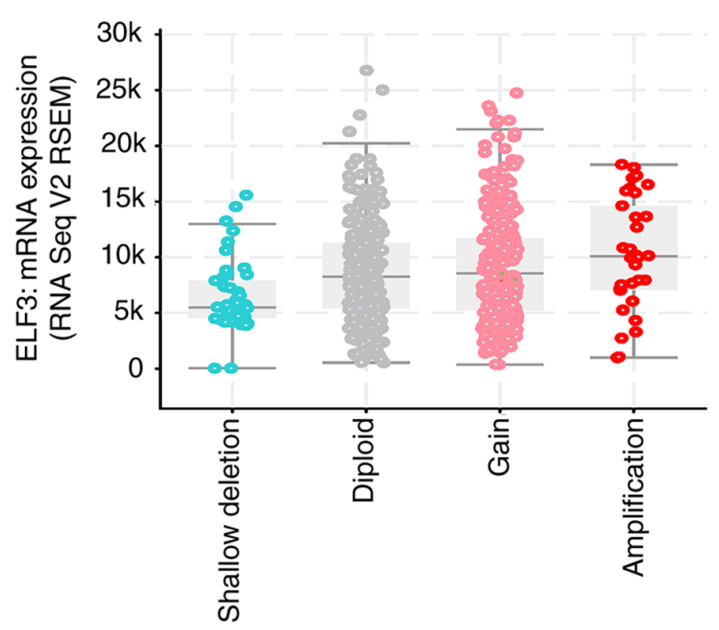

E

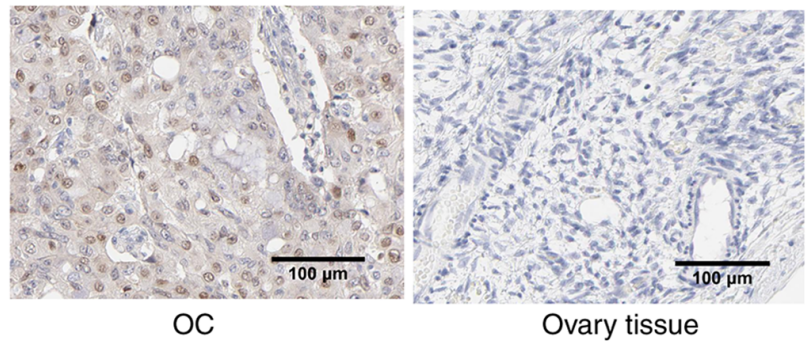

ELF3: Putative copy-number alterations from GISTIC

Figure 1. ELF3 is overexpressed in OC. (A) Chromosomal distribution of overexpressed genes based on TCGA OC cohort using GEPIA; log2FoldChange>3, $\mathrm{q}<0.01$ was considered as the threshold. (B) Expression of ELF3 in OC tissue and normal controls based on TCGA and GTEx data analyzed by GEPIA. (C) Genetic alterations of ELF3 in OC based on the cBioPortal database; 8\% of patients with OC showed ELF3 genetic alternations, most of which were amplifications. (D) Association between ELF3 mRNA expression and genetic copy number alteration in OC, analyzed using cBioPortal. (E) Representative images of ELF3 protein expression in OC and normal ovary tissues, obtained from The Human Protein Atlas. P-value was obtained by one-way ANOVA. "P<0.05. ELF3, E74-like E26 transformation-specific transcription factor 3; OC, ovarian cancer; TCGA, The Cancer Genome Atlas; GEPIA, Gene Expression Profiling Interactive Analysis; OV, ovarian cancer (TCGA); T, tumor; N, normal.

(Fig. 1D), indicating a more complex mechanism underlying ELF3 regulation in OC. Moreover, ELF3 protein expression was analyzed using The Human Protein Atlas. Immunohistochemical staining revealed an increase in ELF3 protein expression in OC compared with non-cancerous ovarian tissue (Fig. 1E). These results implicate that ELF3 is commonly upregulated in OC.

ELF3 expression is associated with cancer stage, patient age and prognosis of $O C$. To investigate the association between ELF3 mRNA expression and the clinical characteristics of OC, UALCAN was used to analyze OC data obtained from TCGA.
As demonstrated in Fig. 2A and B, an increase in ELF3 mRNA expression was associated with a higher OC cancer stage and lower patient age, suggesting that upregulation of ELF3 is associated with an increase in the malignant behavior of OC. Consistent with these findings, Kaplan-Meier survival analysis indicated that high expression of ELF3 is associated with poor prognosis in patients with OC, based on Kaplan-Meier Plotter (Fig. 2C and D) and TCGA (Fig. S1B) cohort analysis. These results suggested that high expression of ELF3 was associated with worse clinicopathological features and poorer prognosis of patients with OC. 
A

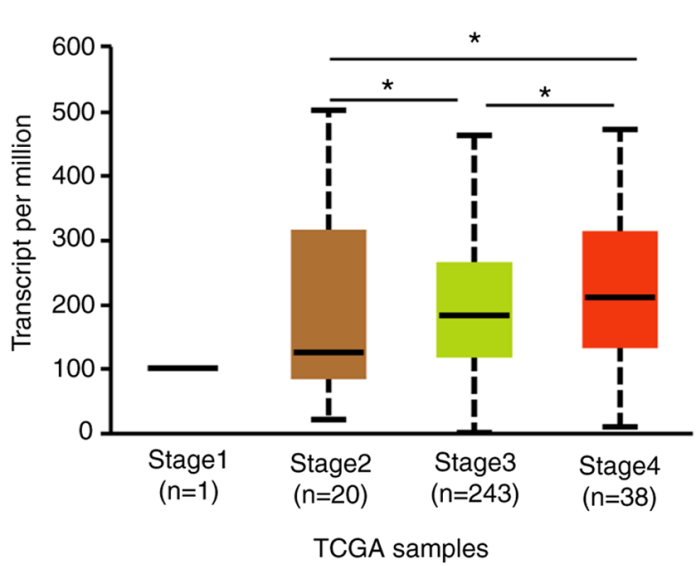

C

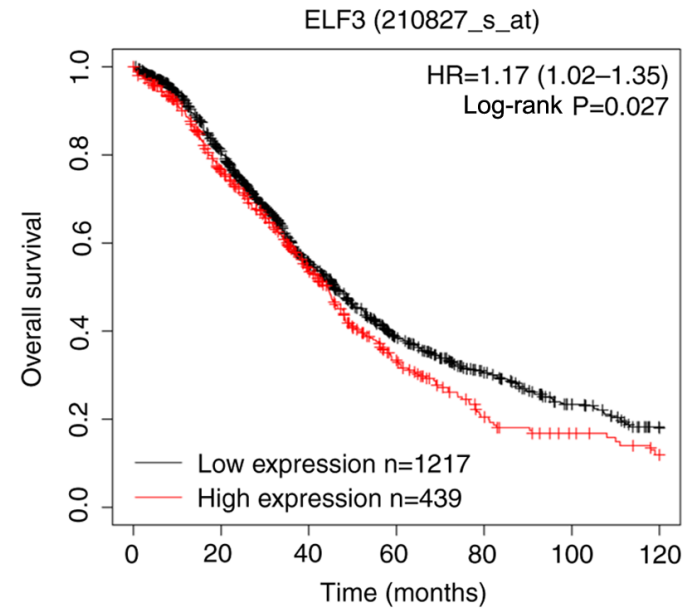

B

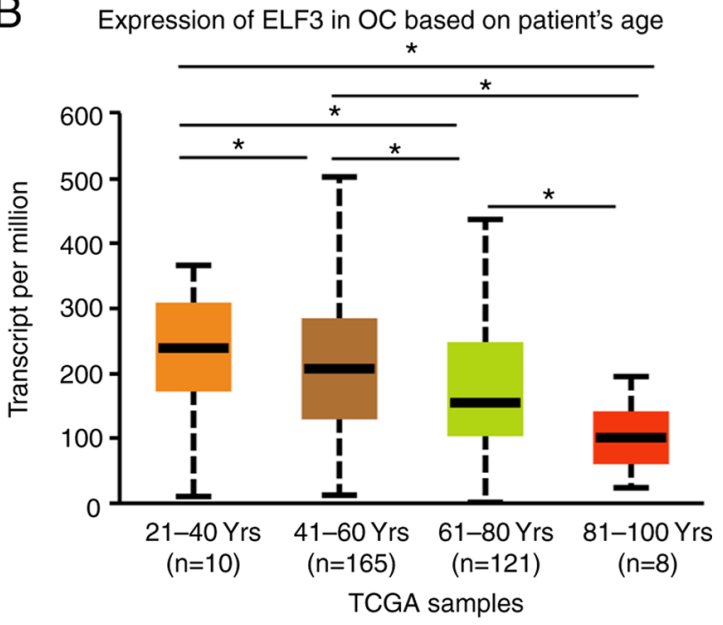

D

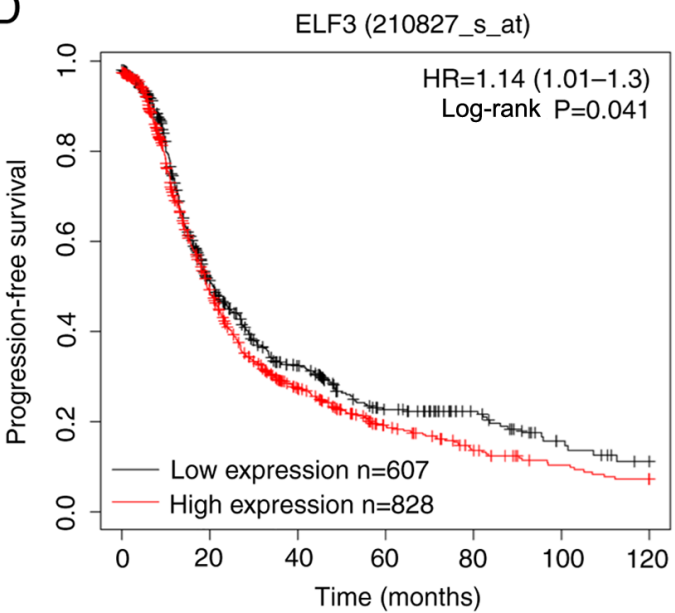

Figure 2. Upregulation of ELF3 is associated with higher individual cancer grade, lower patient age and poorer prognosis. ELF3 expression in OC at (A) different individual cancer stages and (B) different patient ages, based on TCGA cohort in UALCAN. (C) Kaplan-Meier analysis of the effect of ELF3 mRNA expression on the overall survival of patients with OC, based on the Kaplan-Meier Plotter cohort. High and low expression groups were separated based on the best cutoff; low ELF3 expression group, $n=1,217$; and high ELF3 expression group, $n=439$. (D) Kaplan-Meier analysis of the effect of ELF3 mRNA expression on the progression-free survival of patients with OC, based on the Kaplan-Meier Plotter online cohort. High and low expression groups were separated based on the best cutoff; low ELF3 expression group, $n=607$; and high ELF3 expression group, $n=828$. P-values were obtained by one-way ANOVA or the log-rank test. ${ }^{*} \mathrm{P}<0.05$. E74-like E26 transformation-specific transcription factor 3; OC, ovarian cancer; TCGA, The Cancer Genome Atlas; HR, hazard ratio.

ELF3 promotes the proliferation of OC cells and the growth of xenograft tumors in mice. To determine whether ELF3 was associated with the proliferation of OC cells, ELF3 protein expression was evaluated in six ovarian cancer cell lines by western blot analysis (Fig. S1A). A2780 cells (which express endogenous ELF3 at low levels) were selected for ELF3 overexpression analysis (lentivirus infection), and SKOV3 cells (which exhibit high levels of endogenous ELF3 expression) for ELF3 siRNA-knockdown. Clonogenic and proliferation assays were then performed to evaluate the effects of ELF3 on OC cell proliferation. As demonstrated in Fig. 3A, overexpression of ELF3 increased the clonogenic ability of A2780 cells, while ELF3-knockdown reduced the clonogenic ability of SKOV3 cells. Growth curve assays demonstrated that ELF3 overexpression increased the proliferation rate of A2780 cells, while knockdown suppressed the proliferation rate of SKOV3 cells (Fig. 3B). Furthermore, a cell-derived xenograft model was established to investigate the effect of ELF3 on tumor growth. A2780 cells with ELF3 overexpression (and the corresponding control) were subcutaneously injected into nude mice ( $n=5$ per group), and overexpression significantly increased the growth rate of the xenografted tumors (Fig. 4A); $\mathrm{H} \& \mathrm{E}$ staining confirmed OC cell tumorigenesis (Fig. 4B). Furthermore, overexpression of ELF3 in A2780 cells resulted in increased tumor growth (Fig. 4C) and tumor mass (Fig. 4D). Collectively, these results revealed that ELF3 promoted OC cell proliferation and tumor growth in vitro and in vivo.

ELF3 overexpression reduces cisplatin sensitivity of OC cells. To investigate the association between ELF3 and OC cell sensitivity to cisplatin, the expression of ELF3 in cisplatin-resistant A2780 (A2780/DDP) and SKOV3 (SKOV3/DDP) cells was detected using western blotting and RT-qPCR. As demonstrated in Fig. 5A and B, ELF3 expression was upregulated in A2780/DDP and SKOV3/DDP cells compared with cisplatin-sensitive A2780 and SKOV3 cells. A2780 cells with ELF3 overexpression and SKOV3 cells with ELF3-knockdown were used to evaluate the effect of ELF3 on OC cell sensitivity 
A
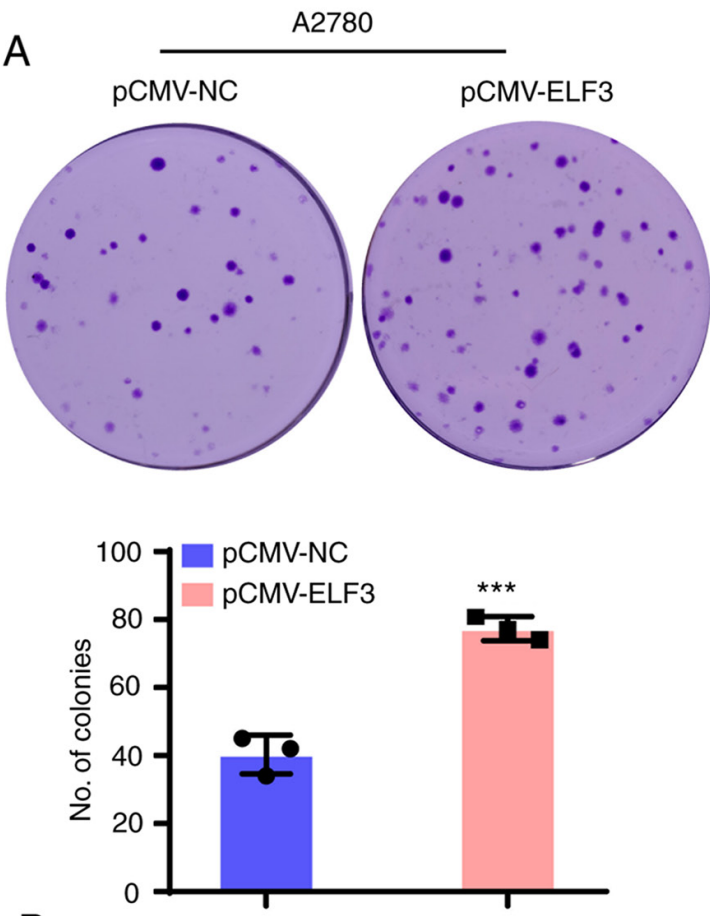

B

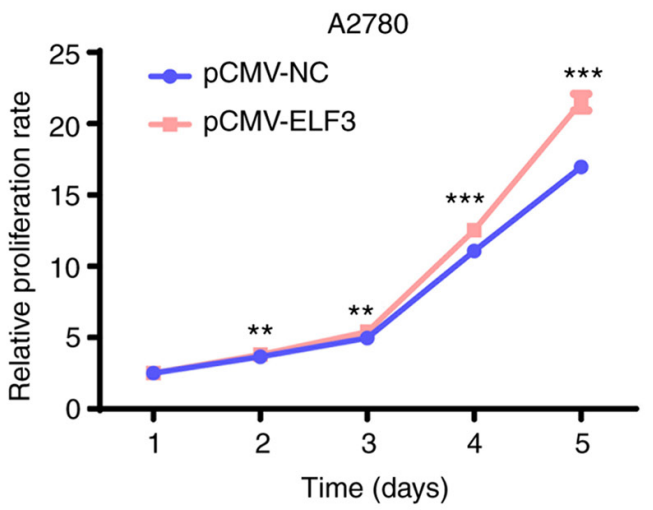

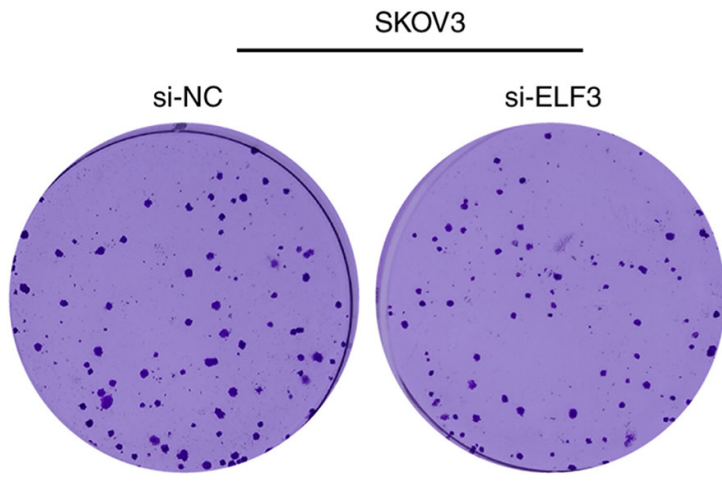
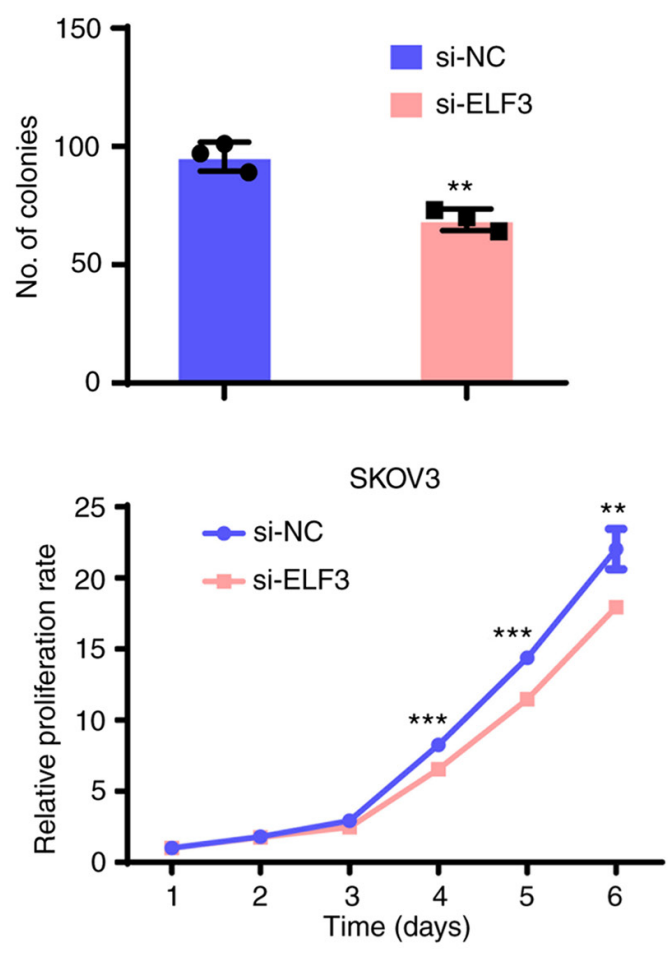

Figure 3. ELF3 promotes ovarian cancer cell proliferation. (A) Overexpression of ELF3 promoted the clonogenic ability of A2780 cells, while ELF3-knockdown reduced the clonogenic ability of SKOV3 cells. (B) Overexpression of ELF3 promoted the proliferation of A2780 cells, while ELF3-knockdown reduced the proliferative capacity of SKOV3 cells. ${ }^{* *} \mathrm{P}<0.01$ and ${ }^{* * *} \mathrm{P}<0.001$ vs. the NC group. E74-like E26 transformation-specific transcription factor 3; NC, negative control; si, small interfering (RNA).

to cisplatin. A viability assay demonstrated that ELF3 overexpression reduced the cisplatin sensitivity of A2780 cells, and ELF3-knockdown increased the cisplatin sensitivity of SKOV3 cells (Fig. 5C). Western blotting results showed that expression of Bax was decreased, and that of $\mathrm{Bcl} 2$ was increased in ELF3-overexpressing A2780 cells compared with the control cells. While the expression of Bax were increased and $\mathrm{Bcl} 2$ expression wA decreased in ELF3-knockdown SKOV3 cells, compared with the control cells. These results indicated that ELF3 reduced cisplatin-induced apoptosis (Fig. 5D). Collectively, ehe results suggest that ELF3 reduces cisplatin sensitivity of OC cells.

ELF3 activates the mTOR pathway of OC cells in vitro and in vivo. To further investigate the mechanism by which ELF3 promotes OC proliferation and tumor growth, western blotting was used to detect alterations in downstream pathway proteins, following both ELF3 overexpression and knockdown.
Western blotting results showed that the expression of phosphorylated mTOR, P70S6K and 4EBP1 were increased in ELF3-overexpresssing A2780 cells, and decreased in ELF3-knockdown SKOV3 cells, compared with their non-phosphorylated forms (Fig. 6A). Moreover, downstream mTOR pathway proteins, such as phosphorylated mTOR, P70S6K and 4EBP1, were also activated in ELF3-overexpresssing A2780 xenografts (Fig. 6B). These results suggested that ELF3 could be activated mTOR pathway. Collectively, the present study results indicated the promoting effect of ELF3 on OC, thus providing a potential novel target for precision OC treatment.

\section{Discussion}

ELF3 (also referred to as ERT, ESX, EPR-1 and ESE-1) is a member of the ETS family (14) that ELF3 regulates the differentiation of epithelial cells in the small intestine (15), bronchial epithelium (16) and urothelium (17). In previous years, 


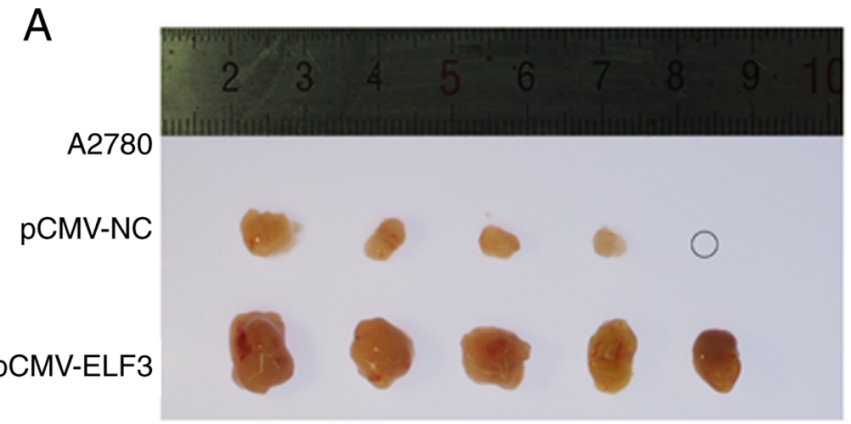

C

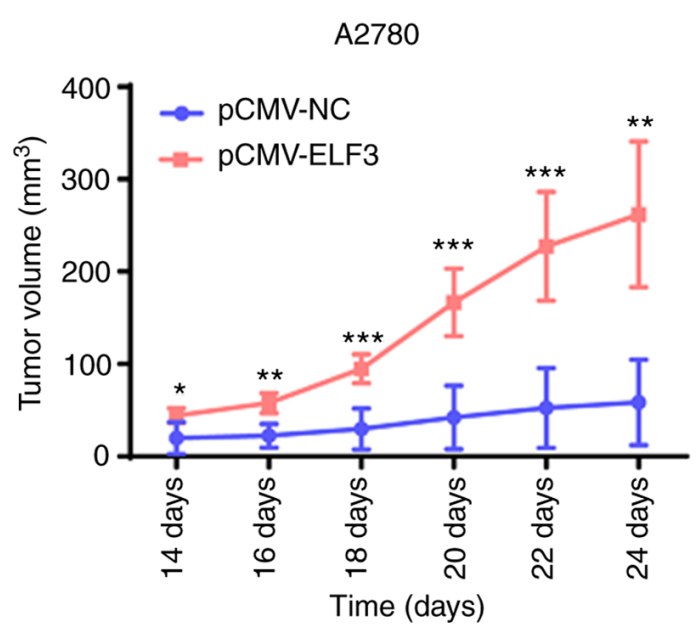

B

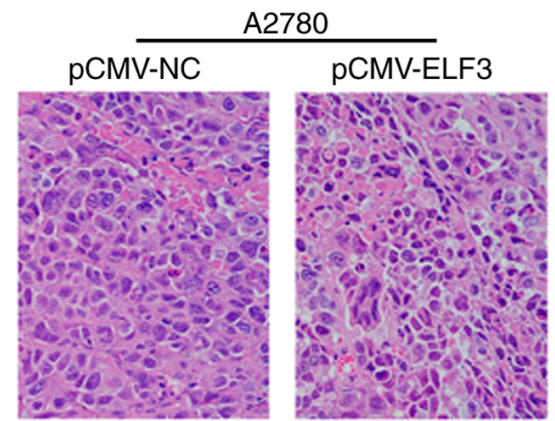

D

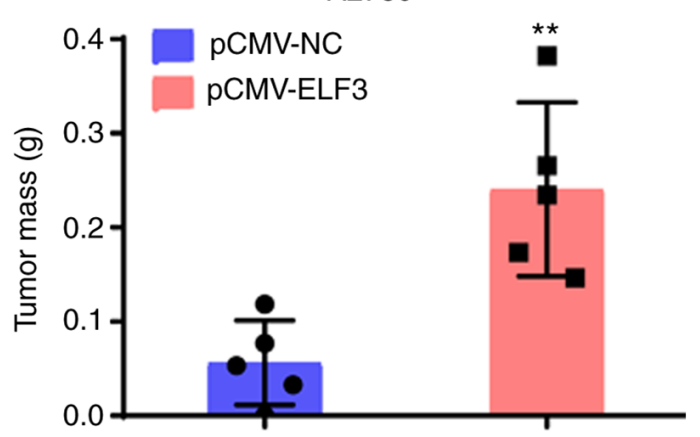

Figure 4. ELF3 promotes ovarian cancer cell tumor growth in nude mouse xenografts. (A) Tumor xenografts from mice subcutaneously injected with A2780 cells overexpressing ELF3 or the control. (B) Hematoxylin and eosin staining of tumor xenografts. (C) Volume and (D) mass of tumors from mice subcutaneously injected with ELF3-overexpressing A2780 cells or the control. ${ }^{*} \mathrm{P}<0.05,{ }^{* *} \mathrm{P}<0.01$ and ${ }^{* * * *} \mathrm{P}<0.001$ vs. the NC group. E74-like E26 transformation-specific transcription factor 3; NC, negative control; si, small interfering (RNA).

increasing evidence has revealed that ELF3 plays a role in the regulation of multiple tumor types. $(7,8,18)$ However, the effect of ELF3 on tumorigenesis and progression remains to be elucidated. Mutations in ELF3 have been observed in gastric cancers, cervical adenocarcinomas, mucinous ovarian carcinomas and ampullary carcinomas (5,17-19). Using TCGA, a previous study revealed that mutations in ELF3 were present in $\sim 6 \%$ of both superficial and invasive tumors in bladder cancer, over half of which were inactivating mutations (20), thus indicating the tumor suppressive role of ELF3 in bladder cancer. By contrast, increased ELF3 expression promoted cellular proliferation, migration and invasiveness in hepatocellular carcinoma (8), colorectal cancer (7), prostate cancer (21) and ampullary carcinoma (22).

Ryland et al (5) analyzed somatic mutations in mucinous $\mathrm{OC}$ and found three mutations of ELF3 by exome sequencing. The mutations of ELF3 in mucinous ovarian cancer were predicted as deleterious, indicating a suppressive role for ELF3 in mucinous OC. Yeung et al (6) revealed that ELF3 was upregulated in long-term OC survivors compared with short-term survivors, and that ELF3 suppressed OC cell proliferation by reversing epithelial-mesenchymal transition (EMT).

In contrast with the findings of a previous study (6), the results of the present study revealed that ELF3, a markedly upregulated transcription factor in high-grade serious OC, was associated with a poor prognosis, and promoted cellular proliferation in vitro and in vivo.
According to the present study, genes that were found to be upregulated in OC (using TCGA) were screened, and due to its increased expression, ELF3 was selected as a biomarker of OC. Unlike the unequal grouping in Yeung et al (low ELF3 expression, $n=15$; high ELF3 expression, $n=299$ ) (6), patients with OC in TCGA cohort were my equally divided into low $(n=211)$ and high $(n=212)$ ELF3 expression groups in the present study. Kaplan-Meier survival analysis indicated that high expression of ELF3 was related to the poorer overall and progression-free survival of patients with OC. Moreover, increased expression of ELF3 was associated with a higher cancer stage and a lower patient age, indicating the oncogenic effect of ELF3 in OC. Subsequent clonogenic, proliferation and tumor xenograft assays confirmed the role of ELF3 in OC promotion. mTOR has emerged as a critical factor in human cancer, regulating protein synthesis, growth, metabolism, aging, regeneration and autophagy $(23,24)$. ELF3 has previously been reported to promote EMT (9), as well as PI3K/AKT and ERK pathway activation (18), though to the best of our knowledge, the association between ELF3 regulation and the mTOR pathway has not previously been reported. In the present study, ELF3 was found to activate the mTOR pathway in OC cells and xenografts by western blotting; however, further investigation is required to confirm the activation effect of ELF3 on the mTOR pathway in OC.

Cisplatin is a chemotherapeutic agent widely used for the treatment and management of OC. However, despite 
A
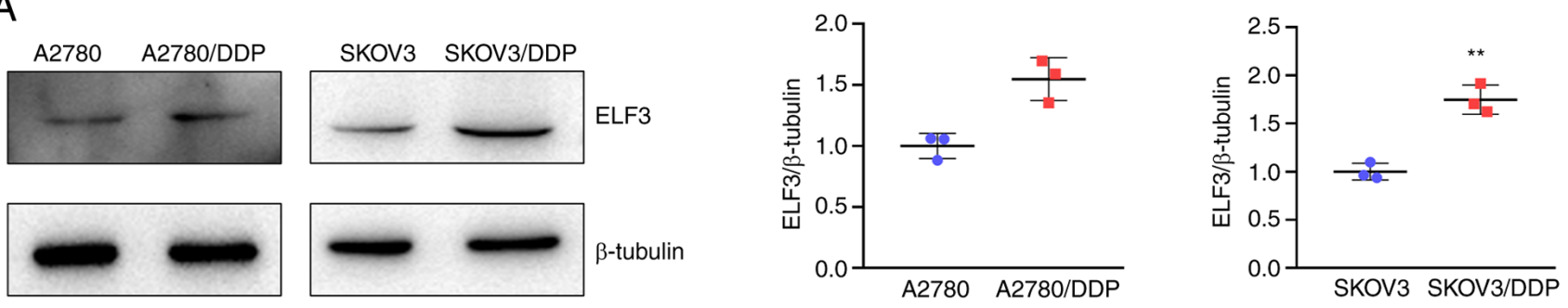

B

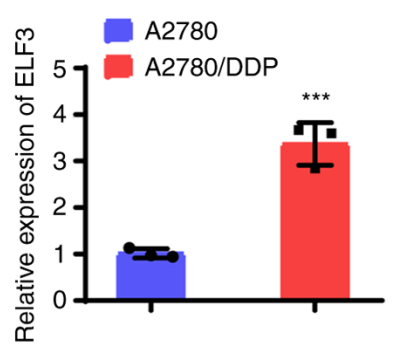

D
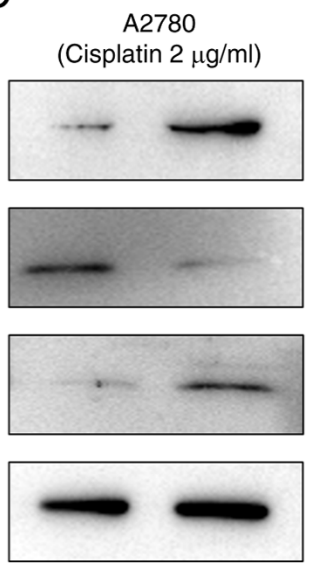

pCMV-NC pCMV-ELF3

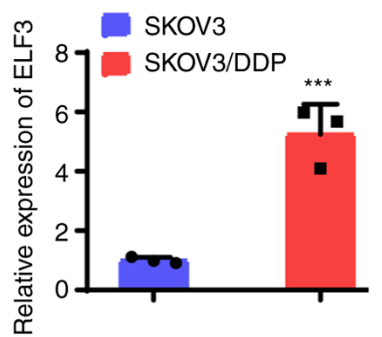

SKOV3

(Cisplatin $5 \mu \mathrm{g} / \mathrm{ml}$ )
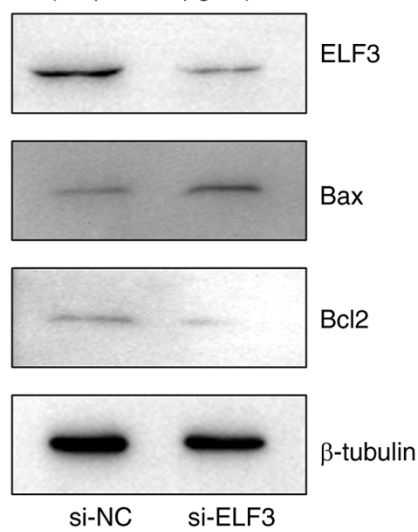

C
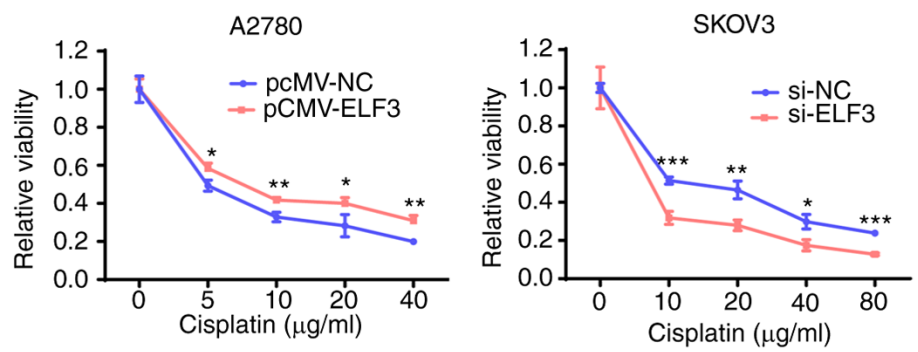

A2780 (Cisplatin $2 \mu \mathrm{g} / \mathrm{ml}$ )

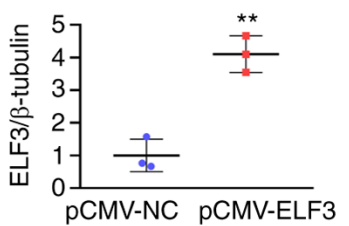

SKOV3 (Cisplatin $5 \mu \mathrm{g} / \mathrm{ml}$ )
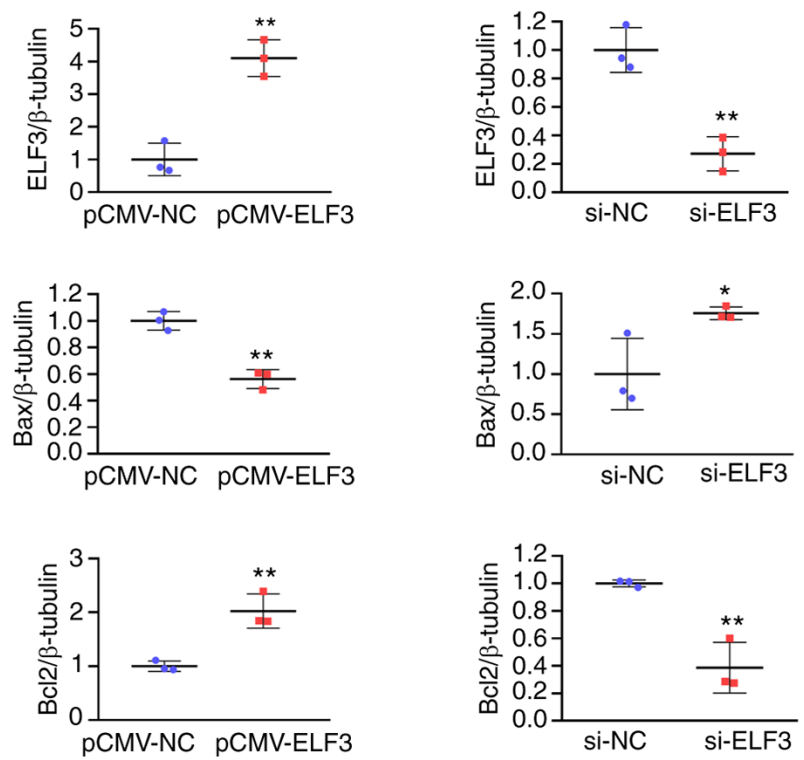

Figure 5. ELF3 overexpression is associated with cisplatin resistance of ovarian cancer cells. (A) Western blotting of ELF3 expression in cisplatin-sensitive and -resistant A2780 cells or SKOV3 cells. The expression of ELF3 is increased in cisplatin-resistant cell lines compared with cisplatin-sensitive cells (B) Reverse transcription-quantitative PCR detection of ELF3 mRNA expression in cisplatin-resistant A2780 and SKOV3 cells compared with the control. (C) ELF3 overexpression decreased the cisplatin sensitivity of A2780 cells, while ELF3 knockdown increased the sensitivity of cisplatin of SKOV3 cells. (D) Western blot analysis of Bax and Bcl2 protein expression in A2780 cells with ELF3 overexpression, and SKOV3 cells with ELF3-knockdown. Experiments were performed in triplicate. ${ }^{*} \mathrm{P}<0.05,{ }^{* *} \mathrm{P}<0.01$ and ${ }^{* * * *} \mathrm{P}<0.001$ vs. the NC group. E74-like E26 transformation-specific transcription factor 3 ; NC, negative control; si, small interfering (RNA); A2780/DDP, cisplatin-resistant A2780 cells; SKOV3/DDP, cisplatin-resistant SKOV3 cells.

an initial response to treatment, $\sim 70 \%$ of patients with OC experience cisplatin resistance and tumor recurrence (25). A previous study revealed that chemotherapy resistance was associated with cancer stem cells (26), the notch receptor/hes family bHLH transcription factor 1 signaling pathway (27), the hypoxia-inducible factor 1 pathway (28) and apoptosis $(29,30)$. However, to the best of our knowledge, the association between ELF3 and OC sensitivity to chemotherapy has not been previously reported. The present study reported that ELF3 was upregulated in cisplatin-resistant OC cells, and that ELF3 reduced cisplatin sensitivity by inhibiting apoptosis. Notably, mTOR signaling (promoting cisplatin resistance) was reported in non-small cell lung cancer, OC and hepatocellular carcinoma (31-33), suggesting that ELF3 reduces cisplatin sensitivity through activation of the mTOR pathway. However, this speculation requires further experimental confirmation.

In conclusion, the results of the present study demonstrated that ELF3 was upregulated in OC, which was associated with poor clinical characteristics. Increased expression of ELF3 promoted the progression, and reduced the chemotherapeutic sensitivity, of OC by activating 
A

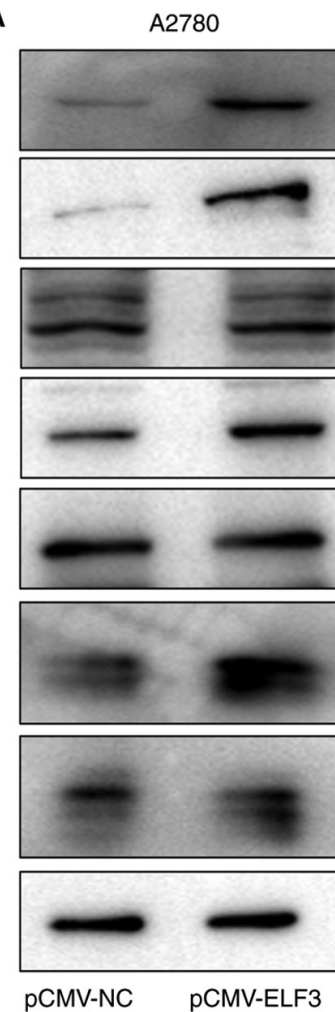

$\mathrm{A} 2780$
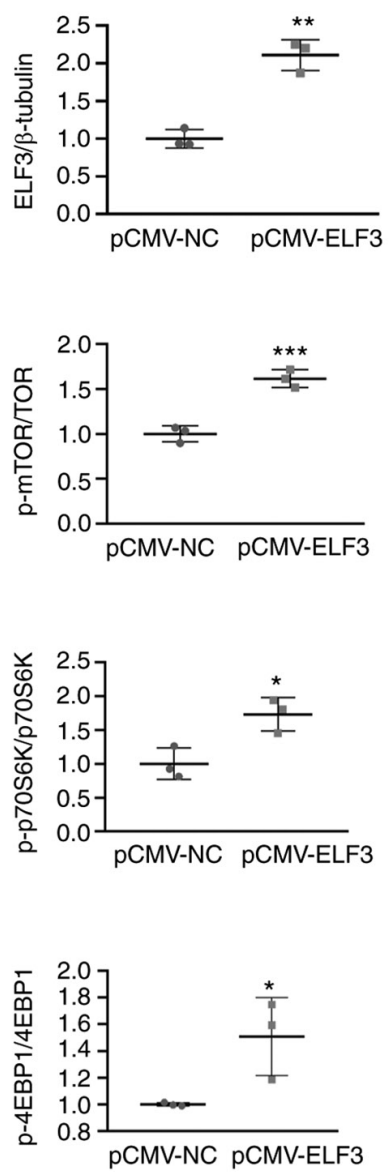
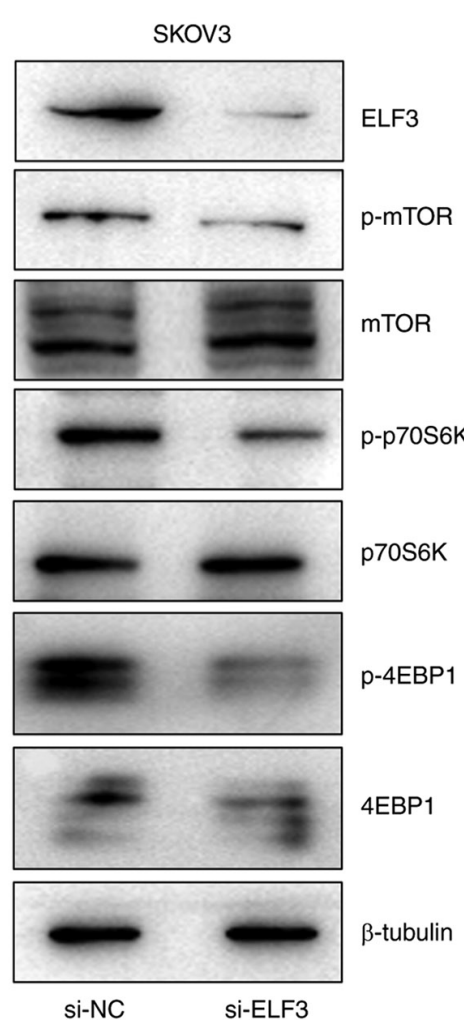

SKOV3
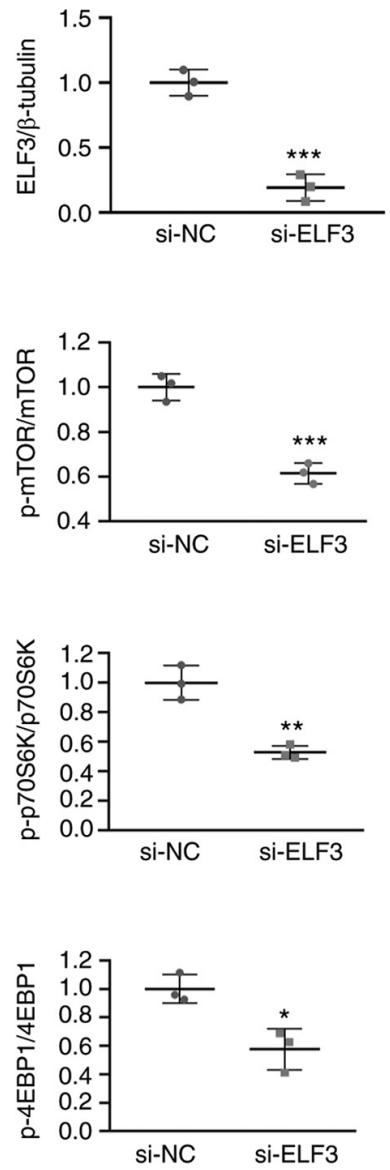

B
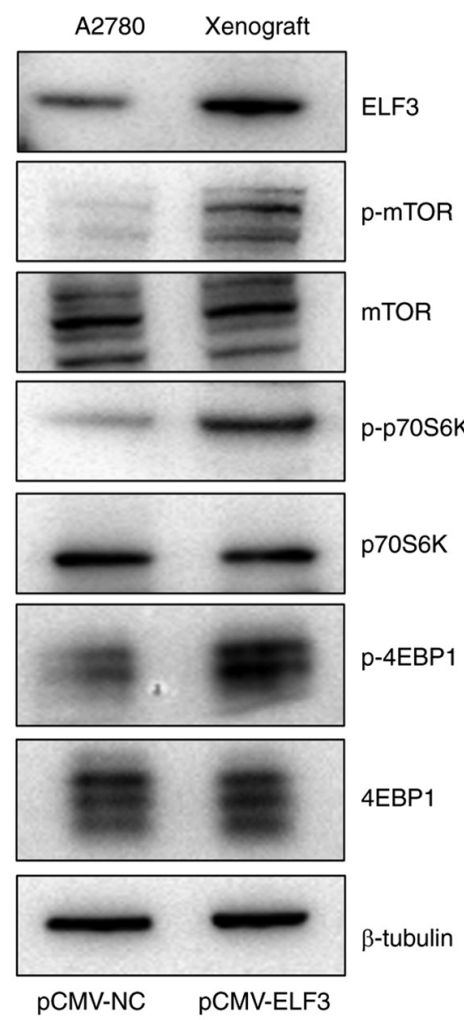

A2780 xenograft
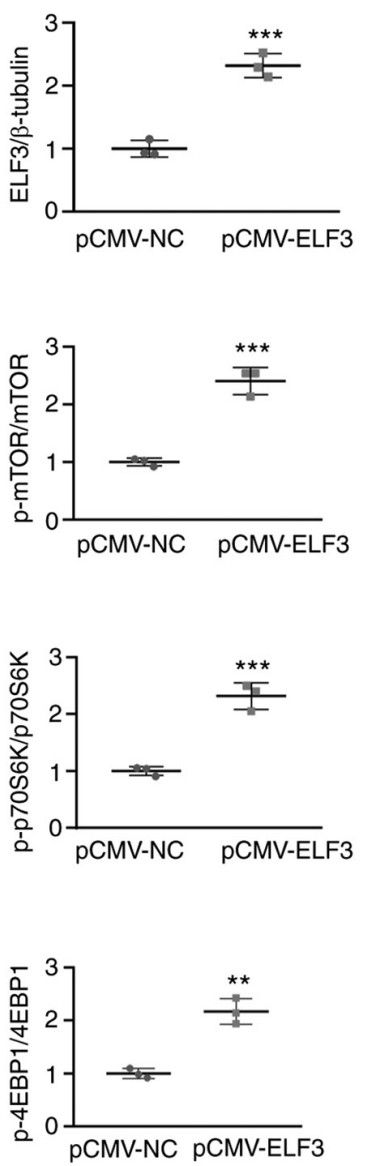

Figure 6. ELF3 activates the mTOR pathway of ovarian cancer cells and xenografts. (A) Western blot analysis of mTOR pathway protein expression in A2780 cells overexpressing ELF3, and SKOV3 cells with ELF3-knockdown. Experiments were performed in triplicate. (B) Western blot analysis of mTOR pathway proteins in A2780 cell xenografts with ELF3 overexpression. Experiments were performed in triplicate. ${ }^{*} \mathrm{P}<0.05,{ }^{* *} \mathrm{P}<0.01$ and ${ }^{* * *} \mathrm{P}<0.001$ vs. the NC group. E74-like E26 transformation-specific transcription factor 3; NC, negative control; si, small interfering (RNA); p-, phosphorylated; 4EBP1, eukaryotic translation initiation factor 4E-binding protein 1 . 
the mTOR pathway, thus providing novel targets for the treatment of OC.

\section{Acknowledgements}

The authors would like to thank the Key Laboratory of Gynecologic Oncology in Universities of Shandong (Jinan, China) for instrument availability.

\section{Funding}

No funding was received.

\section{Availability of data and materials}

The datasets used and/or analyzed during the current study are available from the corresponding author on reasonable request.

\section{Authors' contributions}

GZ and YL were responsible for study conception and design. SW and RZ acquired the data, which was analyzed and interpreted by YL and WL. GZ supervised the study. All authors wrote, reviewed and revised the manuscript. All authors have read and approved the final manuscript. SW and YL confirm the authenticity of all the raw data.

\section{Ethics approval and consent to participate}

All animal experiments were performed with the approval of the Shandong University Animal Care and Use committee.

\section{Patient consent for publication}

Not applicable.

\section{Competing interests}

The authors declare that they have no competing interests.

\section{References}

1. Doherty JA,Peres LC, Wang C, Way GP, GreeneCS and Schildkraut JM: Challenges and opportunities in studying the epidemiology of ovarian cancer subtypes. Curr Epidemiol Rep 4: 211-220, 2017.

2. Lheureux S, Gourley C, Vergote I and Oza AM: Epithelial ovarian cancer. Lancet 393: 1240-1253, 2019.

3. Reid BM, Permuth JB and Sellers TA: Epidemiology of ovarian cancer: A review. Cancer Biol Med 14: 9-32, 2017.

4. Sizemore GM, Pitarresi JR, Balakrishnan S and Ostrowski MC: The ETS family of oncogenic transcription factors in solid tumours. Nat Rev Cancer 17: 337-351, 2017.

5. Ryland GL, Hunter SM, Doyle MA, Caramia F, Li J, Rowley SM, Christie M, Allan PE, Stephens AN, Bowtell DD, et al: Mutational landscape of mucinous ovarian carcinoma and its neoplastic precursors. Genome Med 7: 87, 2015.

6. Yeung TL, Leung CS, Wong KK, Gutierrez-Hartmann A, Kwong J, Gershenson DM and Mok SC: ELF3 is a negative regulator of epithelial-mesenchymal transition in ovarian cancer cells. Oncotarget 8: 16951-16963, 2017.

7. Wang JL, Chen ZF, Chen HM, Wang MY, Kong X, Wang YC, Sun TT, Hong J, Zou W, Xu J and Fang JY: Elf3 drives $\beta$-catenin transactivation and associates with poor prognosis in colorectal cancer. Cell Death Dis 5: e1263, 2014.
8. Zheng L, Xu M, Xu J, Wu K, Fang Q, Liang Y, Zhou S, Cen D, Ji L, Han W and Cai X: ELF3 promotes epithelial-mesenchymal transition by protecting ZEB1 from miR-141-3p-mediated silencing in hepatocellular carcinoma. Cell Death Dis 9: 387, 2018.

9. Tang Z, Li C, Kang B, Gao G, Li C and Zhang Z: GEPIA: A web server for cancer and normal gene expression profiling and interactive analyses. Nucleic Acids Res 45W: W98-W102, 2017.

10. Gao J, Aksoy BA, Dogrusoz U, Dresdner G, Gross B, Sumer SO, Sun Y, Jacobsen A, Sinha R, Larsson E, et al: Integrative analysis of complex cancer genomics and clinical profiles using the cBioPortal. Sci Signal 6: pl1, 2013.

11. Chandrashekar DS, Bashel B, Balasubramanya SAH, Creighton CJ, Ponce-Rodriguez I, Chakravarthi BVSK and Varambally S: UALCAN: A portal for facilitating tumor subgroup gene expression and survival analyses. Neoplasia 19: 649-658, 2017.

12. Nagy Á, Lánczky A, Menyhárt O and Győrffy B: Validation of miRNA prognostic power in hepatocellular carcinoma using expression data of independent datasets. Sci Rep 8: 9227, 2018.

13. Livak KJ and Schmittgen TD: Analysis of relative gene expression data using real-time quantitative PCR and the 2(-Delta Delta C(T)) method. Methods 25: 402-408, 2001.

14. Sharrocks AD: The ETS-domain transcription factor family. Nat Rev Mol Cell Biol 2: 827-837, 2001.

15. Flentjar N, Chu PY, Ng AY, Johnstone CN, Heath JK, Ernst M, Hertzog PJ and Pritchard MA: TGF-betaRII rescues development of small intestinal epithelial cells in Elf3-deficient mice. Gastroenterology 132: 1410-1419, 2007.

16. Oliver JR, Kushwah R, Wu J, Pan J, Cutz E, Yeger H, Waddell TK and $\mathrm{Hu}$ J: Elf3 plays a role in regulating bronchiolar epithelial repair kinetics following Clara cell-specific injury. Lab Invest 91: 1514-1529, 2011.

17. Böck M, Hinley J, Schmitt C, Wahlicht T, Kramer S and Southgate J: Identification of ELF3 as an early transcriptional regulator of human urothelium. Dev Biol 386: 321-330, 2014.

18. Wang H, Yu Z, Huo S, Chen Z, Ou Z, Mai J, Ding S and Zhang J: Overexpression of ELF3 facilitates cell growth and metastasis through PI3K/Akt and ERK signaling pathways in non-small cell lung cancer. Int J Biochem Cell Biol 94: 98-106, 2018.

19. Ojesina AI, Lichtenstein L, Freeman SS, Pedamallu CS, Imaz-Rosshandler I, Pugh TJ, Cherniack AD, Ambrogio L, Cibulskis K, Bertelsen B, et al: Landscape of genomic alterations in cervical carcinomas. Nature 506: 371-375, 2014.

20. Guo G, Sun X, Chen C, Wu S, Huang P, Li Z, Dean M, Huang Y, Jia W, Zhou Q, et al: Whole-genome and whole-exome sequencing of bladder cancer identifies frequent alterations in genes involved in sister chromatid cohesion and segregation. Nat Genet 45: 1459-1463, 2013.

21. Longoni N, Sarti M, Albino D, Civenni G, Malek A, Ortelli E, Pinton S, Mello-Grand M, Ostano P, D'Ambrosio G, et al: ETS transcription factor ESE1/ELF3 orchestrates a positive feedback loop that constitutively activates NF- $\kappa \mathrm{B}$ and drives prostate cancer progression. Cancer Res 73: 4533-4547, 2013.

22. Yachida S, Wood LD, Suzuki M, Takai E, Totoki Y, Kato M, Luchini C, Arai Y, Nakamura H, Hama N, et al: Genomic sequencing identifies ELF3 as a driver of ampullary carcinoma. Cancer Cell 29: 229-240, 2016.

23. Guertin DA and Sabatini DM: Defining the role of mTOR in cancer. Cancer Cell 12: 9-22, 2007.

24. Murugan AK: mTOR: Role in cancer, metastasis and drug resistance. Semin Cancer Biol 59: 92-111, 2019.

25. Agarwal R and Kaye SB: Ovarian cancer: Strategies for overcoming resistance to chemotherapy. Nat Rev Cancer 3: 502-516, 2003.

26. Li SS, Ma J and Wong AST: Chemoresistance in ovarian cancer: Exploiting cancer stem cell metabolism. J Gynecol Oncol 29: e32, 2018 .

27. Islam SS and Aboussekhra A: Sequential combination of cisplatin with eugenol targets ovarian cancer stem cells through the Notch-Hes1 signalling pathway. J Exp Clin Cancer Res 38: 382,2019

28. Ai Z, Lu Y, Qiu S and Fan Z: Overcoming cisplatin resistance of ovarian cancer cells by targeting HIF-1-regulated cancer metabolism. Cancer Lett 373: 36-44, 2016.

29. Li X, Chen W, Jin Y, Xue R, Su J, Mu Z, Li J and Jiang S: MiR-142-5p enhances cisplatin-induced apoptosis in ovarian cancer cells by targeting multiple anti-apoptotic genes. Biochem Pharmacol 161: 98-112, 2019.

30. Rada M, Nallanthighal S, Cha J, Ryan K, Sage J, Eldred C, Ullo M, Orsulic S and Cheon DJ: Inhibitor of apoptosis proteins (IAPs) mediate collagen type XI alpha 1-driven cisplatin resistance in ovarian cancer. Oncogene 37: 4809-4820, 2018. 
31. Gong T, Cui L, Wang H, Wang $\mathrm{H}$ and Han N: Knockdown of KLF5 suppresses hypoxia-induced resistance to cisplatin in NSCLC cells by regulating HIF-1 $\alpha$-dependent glycolysis through inactivation of the PI3K/Akt/mTOR pathway. J Transl Med 16: $164,2018$.

32. Wantoch von Rekowski K, König P, Henze S, Schlesinger M, Zawierucha P, Januchowski R and Bendas G: Insight into cisplatin-resistance signaling of W1 ovarian cancer cells emerges mTOR and HSP27 as targets for sensitization strategies. Int J Mol Sci 21: 9240, 2020
33. Sheng J, Shen L, Sun L, Zhang X, Cui R and Wang L: Inhibition of PI3K/mTOR increased the sensitivity of hepatocellular carcinoma cells to cisplatin via interference with mitochondrial-lysosomal crosstalk. Cell Prolif 52: e12609, 2019.

(c) (i) 9 This work is licensed under a Creative Commons cc) International (CC BY-NC-ND 4.0) License. 